\section{$9^{\text {HI }}$ INTERNATIONAL CONFERENCE ON
THE EUROPEAN ENERGY MARKET}
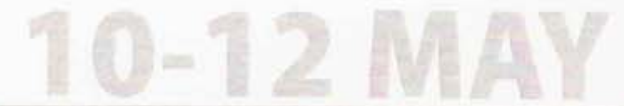

The International Conference on the European Energy Market (EEM12) is a premier forum for the exchange of ideas, open and direct discussion on the development of the energy markets in Europe.

The EEM12, taking place this year in the beautiful landscape of Florentine hills and palaces, will assess the latest developments in:

- ACHIEVEMENT OF THE EU INTERNAL MARKET

- RESPONSETO CLIMATE CHANGE

- SECURING EUROPEAN ENERGY SUPPLY

- COMBINING EUROPEAN"ENERGY PILLARS"INTO A SINGLEEU POLICY

The first day of the EEM12 will be part of the State of the Union Conference chaired by President Josep Borrell, head of the European University Institute and former President of the European Parliament. It will host keynote speakers from European decisions-makers, key industrial actors and prominent academics.

During the following two days, parallel tracks of discussion will cover a variety of energy topics focusing on the latest research developments in Law, Management, Economics and Engineering.

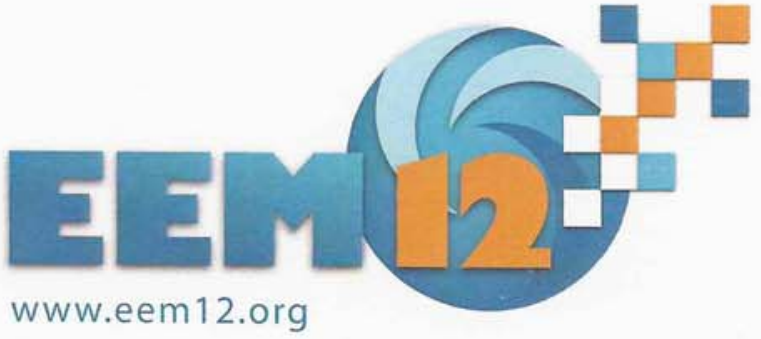

RESEARCH TOPICS INCLUDE:

- ELECTRICITY MARKET POLICIES, STRUCTURES AND RULES

- DEMMAND-SIDE MANAGEMENT OF ENERGY, ENERGY EFFICIENCY

- POWER GENERATION AND RENEWABLE ENERGIES

- TOWARDS A FULLY FUNCTIONING IEM

- GAS, CARBON AND FINANCIAL MARKETS

- COMPETITION LAW, INSTITUTIONAL ANALYSIS OF ENERGY RULES AND INSTITUTIONS

- ENERGY ECONOMICS, ENERGY MANAGEMENT STUDIES, MECHANISM DESIGN

For more information, please visit the EEM12 website: www.eem12.org

\section{Prizes to the two best papers \&} the Loyola de Palacio PhD prize will be awarded.
Contact:
EEM12 Secretariat
Villa Malafrasca,
Via Bocaccio 151
50133 Florence, Italy
Scientific Organisation
EEM12@eui.eu
Logistic Support
EEM12.logistics@eui.eu

The International Conference on the European Energy Market (EEM12) is hosted in Florence - Italy by the two Energy Policy Units at the European University Institute: Florence School of Regulation \& Loyola de Palacio Chair.

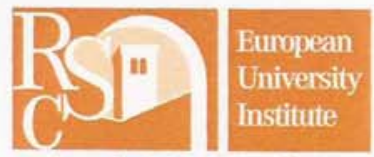

Loyola de Palacio Chair 


\title{
Analysis of Electricity Markets Using Multidimensional Scaling
}

\author{
Filipe Azevedo and J. Tenreiro Machado
}

\begin{abstract}
This paper studies the impact of the energy upon electricity markets using Multidimensional Scaling (MDS). MDS is a computational and statistical technique that produces a spatial representation of similarity between objects through factors of relatedness. MDS represents in a low dimensional map data points whose similarities are defined in a higher dimensional space. Data from major energy and electricity markets is considered. Several maps produced by MDS are presented and discussed revealing that this method is useful for understanding the correlation between them. Furthermore, the results help electricity markets agents hedging against Market Clearing Price (MCP) volatility.
\end{abstract}

Index Terms-- Econometric Models, Electricity Markets, Electricity Price Volatility, Energy Markets, Hedging, Multidimensional Scaling.

\section{NOMENCLATURE}

The notation used throughout the paper is stated below.

$\begin{array}{ll}d_{s t}{ }^{C B} & \text { Citybock distance between each pair of observations } \\ d_{s t}{ }^{S E} & \begin{array}{l}\text { Standardized Euclidean distance between each pair of } \\ \text { observations }\end{array} \\ m & \text { number of observations } \\ x & \text { variable } \\ V & n \times n \text { diagonal matrix whose } j^{\text {th }} \text { diagonal element is } \mathrm{S}(\mathrm{j})^{2}, \\ S & \text { vector of standard deviations } \\ n & \text { number of variables } x\end{array}$

\section{INTRODUCTION}

$\mathrm{D}$ UE to the specific nature of the electricity commodity, namely its non-storability, and due to the necessity of maintaining the electrical system constantly in balance, wide fluctuations on spot market prices occur. This effect, when associated to heat or cold climate waves, can stimulate the spot price to climb up to $1000 \%$ for short periods of time [13]. Therefore, the volatility is unusually high even when compared with other energy markets such as oil or gas. Another implication of the electricity non-storability is the impossibility of transferring a certain amount of energy from

Filipe Azevedo work at Institute of Engineering - Polytechnic of Porto (ISEP/IPP), Rua Dr. António Bernardino de Almeida, 4200-072 Porto, Portugal and he is a researcher at INESC TEC (formerly INESC Porto), Porto, Portugal (e-mail: fta@isep.ipp.pt/filipe.azevedo@inescporto.pt).

J. Tenreiro Machado work at Institute of Engineering - Polytechnic of Porto (ISEP/IPP), Rua Dr. António Bernardino de Almeida, 4200-072 Porto, Portugal (e-mail: jtm@isep.ipp.pt). one part of the world to another one, without considering transmission restrictions. However, besides the instantaneous nature of the product electrical energy, factors like the uncertainty associated to fuel prices, energy demand, generation availability or, even, social and political events have also a high impact on price volatility [14,1,2,15].

Facing this state of affairs, electricity market agents have to deal with the necessity of understanding phenomena that are at the basis of market price evolution. The knowledge of those factors allows decision makers to develop the most adequate set of strategies to sell, or to buy, electric energy in the spot, forward and futures market. In addition, those strategies are important to practice the hedge against electricity market price volatility and, simultaneously, to increase the profits.

Derivatives markets were introduced in electricity markets to allow their agents to eliminate the risk of credit and to turn the market more liquid. This effect is mainly due to the appearance of new agents that operate in traditional markets, that see in electricity markets an opportunity to withdraw dividends and to increase the efficiency in risk management. In addition, some of the new agents described above are also active participants on energy markets, like oil and natural gas.

The first power plants were driven by waterpower or by coal, but today we rely on a larger variety namely, coal, nuclear, natural gas, hydroelectric and petroleum, with a small contribution from solar energy, wind generators and geothermal sources. Figure 1 illustrates the production of electricity in the U.S. by source for the year $2009^{1}$.

From Fig. 1 it is clear that, in the U.S. and for the year 2009 , the main sources for the production of electricity are coal, natural gas and nuclear.

For better understanding electricity markets, price behavior and their correlation with the evolution of energy prices, the Multidimensional Scaling (MDS) technique is used in this paper $[3,4,5,16,6]$.

MDS is adopted in distinct scientific areas such as visualizing time-varying correlations across stock markets $[7,8]$, signal processing $[9,20]$, digital communications [10], adaptive controllers [21] and music [11]. However, presently there are no studies about applying MDS for analyzing electricity market prices and their correlation with the energy price evolution.

Monthly historical data, from July 2007 up to August 2010, for energy and electricity markets is used. It is considered data from July 2007, because OMEL defined prices for Portugal

\footnotetext{
${ }^{1} \mathrm{http}: / /$ www.eia.doe.gov/cneaf/electricity/epm/table1_1.html
} 
and Spain separately due to market splitting, from that date. In Tables 1 and 2 are presented the energy and the electricity markets used in this study. For PJM Interconnection electricity market is used Locational Marginal Price (LMP) Load Weighted Mean Price.

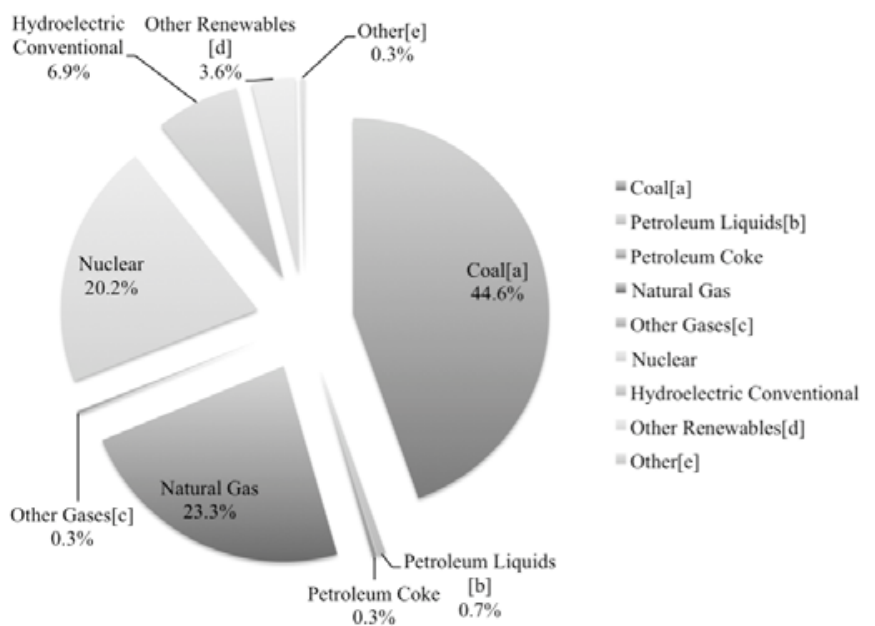

Fig. 1. Sources of electricity in the U.S. during 2009 ([a] Anthracite, bituminous, subbituminous, lignite, waste coal, and coal synfuel. [b] Distillate fuel oil, residual fuel oil, jet fuel, kerosene, and waste oil. [c] Blast furnace gas, propane gas, and other manufactured and waste gases derived from fossil fuels. [d] Wood, black liquor, other wood waste, biogenic municipal solid waste, landfill gas, sludge waste, agriculture byproducts, other biomass, geothermal, solar thermal, photovoltaic energy, and wind. [e] Non-biogenic municipal solid waste, batteries, chemicals, hydrogen, pitch, purchased steam, sulfur, tire-derived fuel, and miscellaneous technologies).

Bearing these ideas in mind, the paper is organized as follows: Section 2 introduces the MDS method. Section 3 presents a case study. Section 4 discusses the results out coming from the MDS processing. Finally Section 5 outlines the main conclusions.

\section{Multidimensional ScAling}

MDS is a technique for the analysis of similarity or dissimilarity data on a set of objects [17]. Its main purpose is to find a configuration of the data points in a low $\mathrm{n}$ dimensional space, such that the original distance between objects in the full-dimensional space is represented with some degree of fidelity by the distances between points in the lowdimensional space. This means that observations that are close together in a high-dimensional space should be close in the low-dimensional space and vice-versa. Many aspects of MDS were originally developed by researchers in the social science community and the method is now widely available in some statistical packages [18].

\section{A. Classical Multidimensional Scaling}

Classical scaling is also known under the names Torgerson scaling and Torgerson-Gower scaling, because the first practical method available was a technique presented in $[3,5,16]$, and it is based on theorems developed in $[4,6]$. The fundamental idea of classical multidimensional scaling is to transform the distance matrix into a cross-product matrix and, then, to find its eigen-decomposition, which gives a Principal
Component Analysis (PCA). Due to this reason in some literature classical multidimensional scaling is also referred as PCA. Like PCA, MDS can be used with supplementary or illustrative elements, which are projected into the dimensions after they have been computed.

\section{B. Nonclassical Multidimensional Scaling}

Nonclassical multidimensional scaling creates a configuration of points whose inter-point distances approximate the given dissimilarities. This is sometimes a too strict requirement and non-metric scaling is designed to relax it a bit. Instead of trying to approximate the dissimilarities themselves, non-metric scaling approximates a nonlinear, but monotonic, transformation of them. Because of the monotonicity, larger or smaller distances on a plot of the output will correspond to larger or smaller dissimilarities, respectively. However, the nonlinearity makes only an attempt to preserve the ordering of dissimilarities. Therefore, there may be contractions or expansions of distances at different scales.

There are two forms of nonclassical multidimensional scaling namely, metric scaling and nonmetric scaling. In metric MDS it is created a configuration of points such that their inter-point distances approximate the original dissimilarities. One measure of the goodness of fit of that approximation is known as the "stress". Nonmetric MDS has a slightly less ambitious goal than metric scaling. Instead of attempting to create a configuration of points, for which the pairwise distances approximate the original dissimilarities, it attempts only to approximate the ranks of the dissimilarities. Another way of saying this is that nonmetric MDS creates a configuration of points whose inter-point distances approximate a monotonic transformation of the original dissimilarities [17,19,12,5,16,19].

It should be noted that MDS maps are insensitive to translations and rotations since they are based on relative measurements. In fact, usually MDs plots are centered merely by some "center of mass" algorithm. Furthermore, often the comparison index between points is abstract and, no units are assigned to the axis of MDS representations. Therefore, MDS charts are interpreted mainly from the point of view of clusters of points and relative distances between them, rather than given some meaning to the absolute coordinates.

\section{CASe Study}

This study aims to study the correlation between energy and electricity markets prices using nonmetric scaling. To achieve this goal, historical data from major energy, stock and electricity markets is used.

\section{A. Energy and Electricity Markets}

Table 1 and 2 present the energy market prices ${ }^{2,3}$, and the electricity markets ${ }^{4,5,6,7}$, respectively.

\footnotetext{
${ }^{2}$ http://tonto.eia.doe.gov/dnav/pet/pet_pri_spt_s1_d.htm

${ }^{3} \mathrm{http}: / /$ www.eia.gov/dnav/ng/ng_sum_lsum_dcu_nus_m.htm

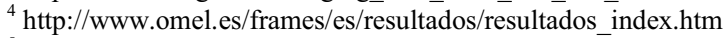

${ }^{5}$ http://www.pjm.com/markets-and-operations/energy/realtime/monthlylmp.aspx
} 
TABLE I

ENERGY MARKETS

\section{Energy market}

West Texas Intermediate

BRENT Crude

Natural Gas
Abbreviation

WTI
BRENT
NG

\section{Country}

USA

UK

USA
TABLE II

ELECTRICITY MARKETS

\begin{tabular}{ccc} 
Electricity market & Abbreviation & Country \\
\hline OMEL Electricity Market & OMEL-PT & Portugal \\
OMEL Electricity Market & OMEL-ES & Spain \\
Energy Exchange Austria & EXAA & Austria \\
Gestore Mercati Energetici & GME & Germany \\
PJM Interconnection & PJM & Italy \\
\hline
\end{tabular}

\section{B. Nonmetric Scaling Stress Function}

In this case study is adopted the Nonmetric Scaling form of Nonclassical MDS. Two measures are compared and used to measure the distance $\left(d_{s t}\right)$ between each pair of observations. In this paper are considered the CityBlock, $d_{s t}^{C B}$, and Standardized Euclidean distance metric function, $d_{s t}^{S E}$, defined as:

$$
\begin{gathered}
d_{s t}^{C B}=\sum_{j=1}^{m}\left|x_{s j}-x_{t j}\right| \\
\left(d_{s t}^{S E}\right)^{2}=\left(x_{s}-x_{t}\right) V^{-1}\left(x_{s}-x_{t}\right)^{\prime}
\end{gathered}
$$

where $x_{s}$ and $x_{t}$ are two distinct observations and $m$ is the total number of points.

The performance of the two alternative indices is compared in the sequel.

\section{Number of Dimensions in MDS}

The variation on the "stress" value with the number of dimensions to use is presented in Fig. 2. The goodness-of-fit criterion used, also known as the "stress", is the sum of squares of the inter-point distances.

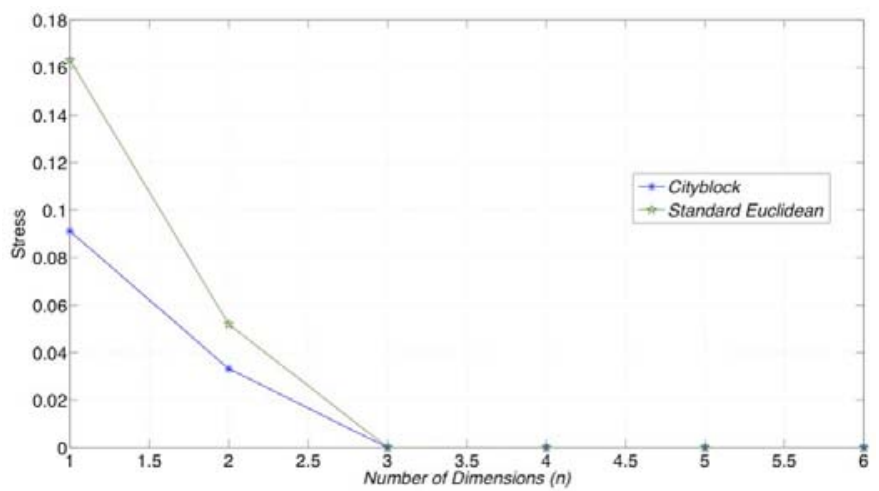

Fig. 2. Stress variation versus the number $\mathrm{n}$ of dimensions of the MDS plot.

\footnotetext{
${ }^{6} \mathrm{http}: / /$ en.exaa.at/market/historical/austria_germany/

${ }^{7} \mathrm{http} / / /$ www.mercatoelettrico.org/En/Statistiche/ME/DatiStorici.aspx
}

From Fig. 2 we conclude that the required number of dimensions to use is $n=3$ for the Cityblock and Standard Euclidean distances. However, we can verify that Cityblock metric function has, for all dimensions $n$ of the MDS plot, lower "stress" values; therefore, in this work will be adopted the metric function Cityblock.

\section{RESULTS}

The nonmetric MDS solution plot of the configuration for $n=3$ is represented in Fig. 3. It is clear the emergence of three major clusters: U.S. PJM electricity market and energy group \{PJM, NG, WTI, BRENT $\}$, Iberian electricity market \{OMEL-PT, OMEL-ES\} and electricity market group \{EXAA, GME\}.

In U.S. the main sources for the production of electricity are coal, natural gas and nuclear. This is the reason why PJM electricity market is closer to natural gas energy markets (NG) than oil markets (WTI and BRENT). Moreover, the natural gas market (NG) used in this case study is for U.S., which reinforces its proximity to the PJM electricity market.

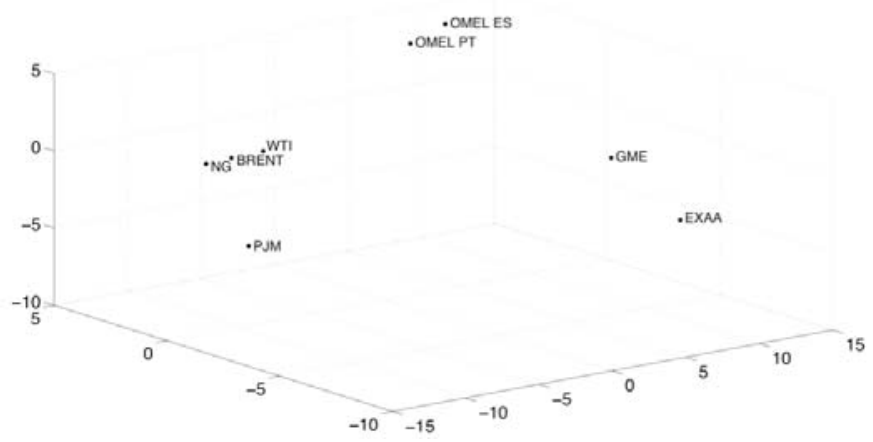

Fig. 3. Nonmetric MDS solution.

To check the fitting of the output MDS configuration and to analyze the disparities, it is useful to analyze the Shepard chart depicted in Fig. 4.

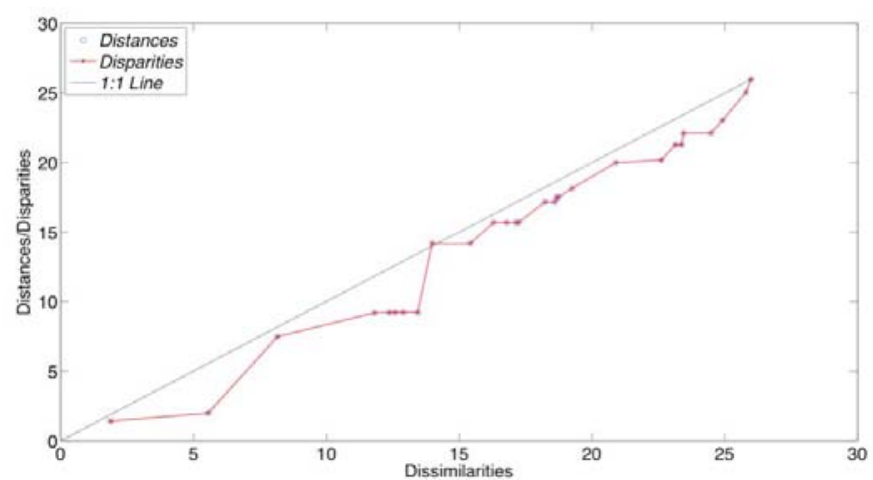

Fig. 4. Shepard plot for $n=3$.

Fig. 4 reveals that MDS has found a configuration of points in three dimensions whose inter-point distances approximates the disparities, which, in turn, are a nonlinear transformation of the original dissimilarities. The concave shape of the disparities as a function of the dissimilarities indicates that 
fitting tends to contract small distances relative to the corresponding dissimilarities. This result is perfectly acceptable in practice and demonstrates that MDS can be easily adopted for the visual analysis of energy and electricity market prices.

\section{CONCLUSIONS}

In this paper we proposed a statistical graphical method for visualizing time-varying correlations between energy market and electricity market behavior. We illustrated the MDS-based method on the basis of monthly price average for three energy markets and five electricity markets.

The results show, clearly, the emergence of three major groups: U.S. PJM electricity market and energy group (PJM, NG, WTI, BRENT\}, Iberian electricity market \{OMEL-PT, OMEL-ES $\}$ and electricity market group \{EXAA, GME\}. From the described groups, natural gas is closer to PJM electricity market then oil group. This is due to the importance of combined cycle power plants upon the electricity production. The natural gas market (NG) used in this case study is for U.S., which reinforces its proximity to the PJM electricity market. In European electricity markets this effect is not so strong.

There are several issues relevant for further research. A first issue concerns applying the proposed method to alternative data sets, to see how informative the method can be in these cases. A second issue concerns incorporating the graphical evidence in an econometric time series model for improving empirical specification strategies

\section{ACKNOWLEDGMENT}

Authors would like to acknowledge GECAD researcher João Soares by the support given to obtain the historical data from electricity and energy markets.

\section{REFERENCES}

\section{Periodicals:}

[1] F. Azevedo, Z. A. Vale, P. B. M. Oliveira and H. M. Khodr, A LongTerm Risk Management Tool For Electricity Markets Using Swarm Intelligence, Elsevier - Electric Power Systems Research 80 (2010) 424433.

[2] F. Azevedo, Z. A. Vale, and P. B. M. Oliveira, "A Decision-Support System Based on Particle Swarm Optimization for Multi-Period Hedging in Electricity Markets," IEEE Transactions on Power Systems 22 (2007)

[3] J. C. Gower, Some Distance Properties of Latent Root and Vector Methods used in Multivariate Analysis," Biometrika 53 (1966) 325-338.

[4] C. Eckart and G. Young, Approximation of One Matrix by Another of Lower Rank, Psychometrika 1 (1936) 211-218.

[5] W. S. Torgerson, Multidimensional Scaling: Theory and Method," Psychometrika 17 (1952) 401-419.

[6] G. Young and A. S. Householder, Discussion of a Set of Point in Terms of their Mutual Distances, Psychometrika 3 (1938) 9-22.

[7] P. J. Groenen and P. H. Franses, Visualizing time-varying correlations across stock markets, Journal of Empirical Finance 7 (2000) 155-172.

[8] J. A. Tenreiro Machado, Gonçalo M. Duarte and Fernando B. Duarte, Identifying Economic Periods and Crisis with the Multidimensional Scaling, Springer Nonlinear Dynamics 64 (2011) 611-622.

[9] M. R. Martínez-Torres, F. J. García, S. L. Marín and S. G. Vázquez, A Digital Signal Processing Teaching Methodology Using ConceptMapping Techniques, IEEE Transactions on Education 48 (2005).
[10] S. Chen, B. Mulgrew and P. M. Grant, A clustering technique for digital communications channel equalization using radial basis function networks, IEEE Trans. Neural Networks 4 (1993) 570-578.

[11] J. A. Tenreiro Machado, A. C. Costa and M. F. M. Lima, Dynamical analysis of compositions, DOI 10.1007/s11071-010-9900-6, (2010).

[12] Y. Takane, F. W. Young and J. Leeuw, Nonmetric Individual Differences Multidimensional Scaling: An Alternating Least Squares Method with Optimal Scaling Features, Psychometrika 42 (1977) 7- 67.

Books:

[13] J. C. Hull, Fundamentals of Futures and Options Markets, 4th Edition, Prentice-Hall, 2002.

[14] M. Shahidehpour and M. Alomoush, Restructured Electrical Power Systems - Operation, Trading, and Volatility, Marcel Dekker Inc, New York, 2001.

[15] P. L. Skantze and M. D. Ilic, Valuation, Hedging and Speculation in Competitive Electricity Markets: A Fundamental Approach, Kluwer Academic Publishers, 2001

[16] W. S. Torgerson, Theory and Methods of Scaling, Wiley, New York, 1958.

[17] I. Borg and P. Groenen, Modern Multidimensional Scaling - Theory and Applications, 2nd Edition, Springer, 2005.

[18] W. Martinez and A. Martinez, Exploratory Data Analysis with MATLAB, Chapman \& Hall/CRC, 2005

[19] T. F. Cox and M. A. Cox, Multimensional Scaling - 2nd Edition, Chapman \& Hall/CRC, 2001

\section{Papers from Conference Proceedings (Published):}

[20] D. Rosario and J. Romano, Multidimensional image processing for remote sensing anomaly detection, Proc. 2nd International Conference on Image Processing Theory Tools and Applications (IPTA), 2010, pp. $471-476$.

[21] S. P. Bingulac, On the compatibility of adaptive controllers (Published Conference Proceedings style), Proc. 4th Annual Allerton Conference Circuits and Systems Theory, New York, 1994, pp. 8-16.

\section{BIOGRAPHIES}

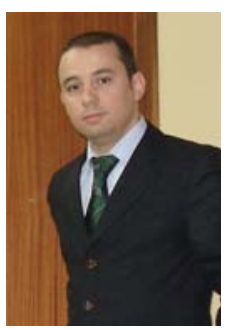

Filipe Azevedo (S'06) received his diploma in 1999, the M.Sc. in 2003, both in Electrical Engineering from Porto University, Portugal, and the Ph.D. degree in 2008 on Electrical Engineering at the University of Trás-os-Montes e Alto Douro (UTAD), Vila Real, Portugal. He is currently a Professor of Power Systems at the Institute of Engineering - Polytechnic of Porto (ISEP/IPP), Portugal, and a at INESC TEC (formerly INESC Porto), Porto, Portugal. His main research interests are Economics applied to Energy Markets, Decision-Support System techniques applied to Economics Engineering problems and Artificial Intelligence (A.I.) applications.

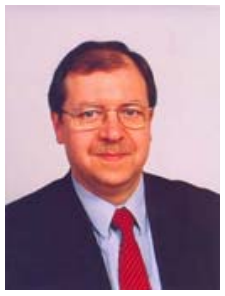

J. A. Tenreiro Machado (M'07-SM'10) was born a 1957, graduated with the 'Licenciatura' (1980), PhD. (1989) and 'Habilitation' (1995) degrees in Electrical and Computer Engineering at the University of Porto. During 1980-1998 he worked as Professor at the Department of Electrical and Computer Engineering of the University of Porto. Since 1998 he is Coordinator Professor at the Institute of Engineering of the Polytechnic Institute of Porto, Department of Electrical Engineering. His main research interests are fractional calculus, nonlinear dynamics, modeling, control, robotics, intelligent transportation systems and evolutionary computing. 